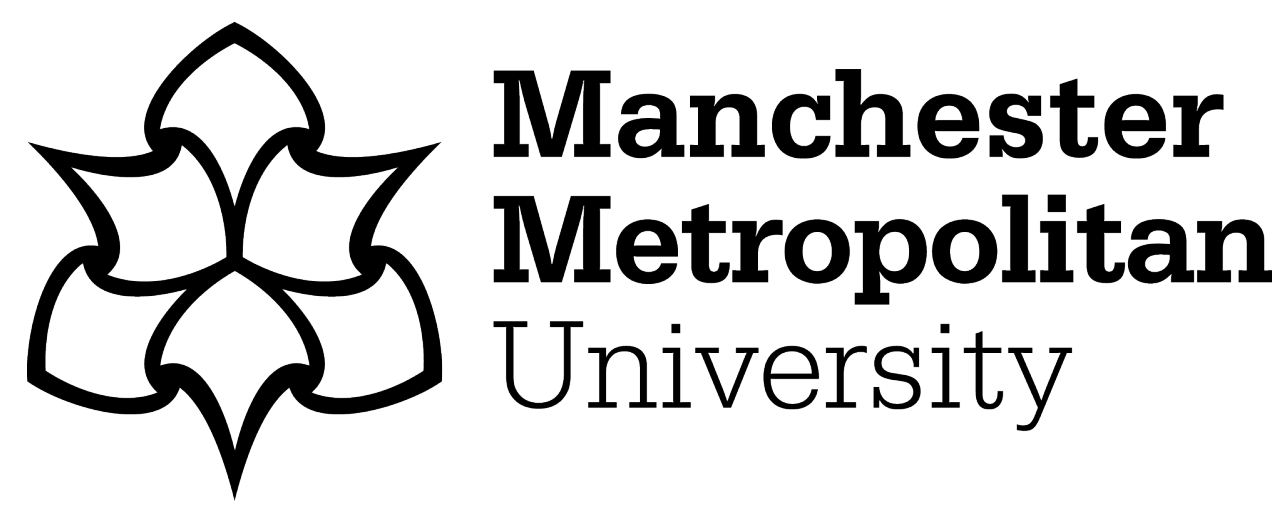

Aeby, G and van Hooff, Jenny (2019) Who gets custody of the friends? Online narratives of changes in friendship networks following relationship breakdown. Families, Relationships and Societies, 8 (3). pp. 411-426. ISSN 2046-7435

Downloaded from: https://e-space.mmu.ac.uk/620849/

Version: Accepted Version

Publisher: Policy Press

DOI: https://doi.org/10.1332/204674318X15271464535444

Please cite the published version 


\section{Who gets custody of the friends? Online narratives of changes in friendship networks following relationship breakdown}

\section{Introduction:}

Based on the analysis of Internet forum data, this paper explores the online narratives of individuals who share their experiences of the loss or change of friendships following a divorce or relationship breakdown. Within this context, online communities operate as a source of support for users facing a critical life event and feeling marginalized or stigmatized by their newly single or divorcee status. Individuals at various stages of the break-up process express their feelings, share advice and collaboratively develop new meanings of friendship practices and norms. They also re-evaluate and reflect back on the role of friendship in their lives, even when no longer single. Previous research has tended to focus on experiences of being in a relationship or unattached, with little sociological attention paid to the transition between coupled and singled status, which is a common experience, with the current divorce rate at $42 \%$, and the $60 \%$ relationship dissolution rate for cohabiting couples in the UK (Office for National Statistics, 2014). The focus here is on the consequences of long-term relationship breakdown for other personal ties beyond the couple, in particular focusing on friendship, which allows us to move beyond a privileging of family and sexual partnerships so that we may consider the relevance of wider social networks and communities (Budgeon, 2006). Drawing on the data, we discuss couple sociality, expectations of friendship, and the role of online communities in providing the support which traditionally maintained friendships may fail to provide.

\section{Background:}

Arguments about the impact of late modern social and demographic transformations have led to suggestions that increasing weight is being given to elected ties, such as friendship, in place of more traditional bonds in contemporary personal life. However, most research (Cronin, 2015; van Hooff, 2015) continues to suggest the centrality of the couple in intimate life, with boundaries carefully reinforced and delineated between friendship and partner bonds (Jamieson, 1998). Research has tended to focus on the experiences of couples (Heaphy et al, 2013; Gabb and Fink, 2015), singles (Reynolds and Taylor, 2005; Sandfield and 
Percy, 2003) or friends (Spencer and Pahl, 2006; Allan, 2008), and where research has examined relationship breakdown it has focused on the consequences of separation for couples and families (for example Bakker et al, 2015), rather than wider networks. By studying individuals' transitions from coupled to 'un-coupled', and the how this impacts on social networks, we illuminate the multiple ways that categories of personal life blur and intersect in practice (Jamieson et al, 2006).

Attempts within sociology to decentre the family and heterosexual couple (Roseneil and Budgeon, 2004; Smart, 2007) in recognition of the diversity of meaningful relationships that people maintain and negotiate beyond traditional structures have focused in particular on the importance of friendship ties. Detraditionalisation theorists (Giddens, 1992; Beck and Beck-Gernsheim, 1995, 2002) posit that we are living through a period of intense social change, which is having a profound impact on our personal relationships. Giddens (1992) identifies the emergence of the 'pure relationship', an internally referential, temporal relationship model based on the principles of choice, equality and personal satisfaction, which is most clearly reflected in the practice of friendship. Those living the most individualized lives often centre their relationships around friendships in a way that reconfigures domestic space and its association with the conjugal couple and nuclear family (Roseneil and Budgeon, 2004: 153). Research into the friendship networks of same-sex people has indicated friends can take on some of the duties traditionally performed by family members (Weeks et al, 2001).

Friendship also works as a catch-all category when, in practice, individuals experience different types of friendship varying in commitment and expectations. Interestingly, the experience of a break-up can illuminate these categories when individuals in the process of de-interlocking their mutual network realise that some friends are not as supportive as expected. In the next paragraphs, after a brief presentation of the data at hand, we will discuss the impact of an intimate relationship breakdown on friendship, friendship in online communities, and how individuals negotiate and re-evaluate friendships.

\section{Data:}

The data were selected from two English-speaking websites with an interface to post questions and answers. The interface was public and the conversation threads were 
accessible to public viewing without membership. As users of Internet forums are aware of the public display and can 'reasonably expect to be observed by strangers' (British Psychological Society, 2006), consent was not asked to collect the posts, which is an ethically accepted procedure (Attard \& Coulson, 2012). Indeed, individuals tend to adjust their personal stories when posting online and use private messages, offered by most websites for registered members, when necessary (Couldry, 2008). Some researchers, especially when wanting to access members-only content, seek the webmaster's permission, which does not entirely solve the question of individual consent even when information on the study is displayed (Paechter, 2012a). Nevertheless, in order to avoid identification, pseudonyms were not indicated and only short quotations were shown.

In addition, we did not focus on single users across conversation threads, but on the content and the dialog. One website was more specifically dedicated to divorce and the other was broader. We conducted a key-words search with the word "friend" associated with adjectives like "mutual”, "joint", "new", "old". As the ex-partner was often called the former "best friend", we excluded posts only focused on the loss of the couple relationship. For the second website, we also specified "break-up / divorce". We selected twenty initial posts (ten per website) with a minimum amount of eight answers from 2009 onwards, leading to a sample of 370 posts. This study was supported by the National Science Foundation as part of a wider grant (2016-2017) awarded to to investigate the recomposition of personal networks following relationship breakdown and was approved by the Ethics committee of the University of

\section{Friendship after an intimate relationship breakdown:}

While friendship occupies a certain idealised form (Rawlins, 1992) within late modern society, within the normative 'hierarchy of intimacy' (Budgeon, 2006), the sexual couple is presumed to take precedence within personal networks. Based on qualitative research into friendship and couple practices, Cronin (2015: 2) argues that the couple is the pivot around which most people organize their lives and value other relationships, with intimacy framed as a finite resource to be distributed using a principle of scarcity. As a result, there is often a tension between the ideal couple relationship and the demands of friendship with the former usually being given priority. This is supported by earlier research (O'Connor, 1992) 
that suggests women tend to select friendships that support their relationships. Friendship is practised alongside and across all of our other relationships (Budgeon, 2006), and as such is a historically and socially contingent relationship that has relational connections to family, couple and society more generally (Cronin, 2015). With couple culture so ingrained that its privileged status is rarely even recognised (Suen, 2015), other intimacies such as friendship are marginalised (Bugdeon, 2008). Rather than operating as a flexible social category, the couple structures social life, with research suggesting a clear demarcation between the family/couple and wider social ties (Ketovkivi, 2012).

With couples privileged as the centre of personal life, they also form the basic unit of socialising, with friends usually perceived as a backdrop with limited emotional significance (Cronin, 2015). This is problematic when the status of an individual changes and they demand more from a friendship. During a relationship, friendships are deprioritised, however during a break-up or other 'existential trial', friendship ties take on an increased emotional intensity which tests the strength of their bond (Rebughini, 2010), which may be more pressure than these thinner friendship ties can bear. The perceived importance of friends in transitional life stages, such as relationship breakdown (Rawlins, 1992), fails to account for the reality of the level of support available from often poorly maintained friendships. Rather than the enduring bond it is often described as, friendship is a set of practices (Cronin, 2015). People have to negotiate friendship on an individual level in the context of cultural scripts of what friendship should look like (Rawlins, 1992), which place an additional strain on the relationship as it is experienced. Nevertheless, friendship has generally been depicted as a positive relationship, described for example by Beck (1992) as a fundamental source of personal support in the context of increasing individualisation.

The users of Internet forums observed in this study had these expectations of friendship as a source of support in challenging times, yet their experiences were usually less straightforward than this. Most users reported the loss of friends as adding unexpected pain to the break-up process. They tried to make sense of the defection by revisiting their friendship history and distributing blame. They explained that they became very focused on their partner and, if any, on their children. They developed relationships with other couples or families, often living nearby, around barbeques, and dinner invitations. Friendship with 
them seemed effortless and fulfilling but, looking back, they were "superficial", mostly based on sharing a common situation. In addition, users (more often male) acknowledged having unintentionally left their partner to do the "heavy lifting in friendship." During the course of the relationships, friends met previous to it either became mutual friends or were cut adrift because of this new focus, as users admitted having neglected to do "friendship maintenance." The ex-partner was also sometimes blamed from this estrangement, as they were described as not really appreciating the personal friends. Nevertheless, before the break-up, users were under the impression that they had a supportive social circle of friends.

Despite the acknowledgment of some shortcomings in handling friendship, the defection of friends is mostly understood as a proof that the users invested in the "wrong" friends. Three categories of friends are mentioned regarding the idea of 'ownership': the mutual or joint friends, the ex-partner's friends, and the users' own friends. While defection is accepted for the ex-partner's friends, disappointing and painful for the mutual friends, the loss of friends who were considered as personal is interpreted as a complete betrayal. Of issue is the blurriness of these boundaries, especially over time, as personal networks of couples tend to interlock. Some friends who were perceived as mutual unexpectedly take the expartner's side. Whereas users have more refined and subtle ways of criticizing the mutual friends for their lack of support, the once personal friends receive unanimous condemnation, as they are expected "to have your back". Recent research (Smart et al, 2012) has highlighted the disappointments involved in difficult friendships, and the ontological insecurity that this may trigger. Unlike partners, friends are expected to have a certain amount of intrinsic flexibility, to be available during emotional trials (Rebughini, 2010), and of more significance in the lives of the unattached (Jamieson et al, 2006), but to play the part of extras in the lives of the coupled.

Over the life course, life transitions favour or hinder the importance of kinship and nonkinship ties in personal networks (Jamieson et al, 2006). The consequences of divorce or break-up are mostly perceived as negative for psychological and social outcomes such as feelings of loneliness, impoverishment of individuals, children's adjustment problems, etc. 
(Amato, 2010). Beyond various practical aspects (e.g. legally divorcing, moving house, dividing material goods, change of name, etc.), divorce has a potentially tremendous impact on relational resources as it may imply a recomposition of personal networks. Indeed, during the couple relationship, couples create a form of social capital, marital capital, stemming from joining their networks, which is compromised by the divorce (Kalmijn, 2003). Divorce or break-up may generate the split of the couple network, and the loss of personal relationships - in particular those formed during the conjugal period (Albeck \& Kaydar, 2002) - results in a lack of social support in a time of emotional and material need. Friendship is related to one's sense of self, what can lead to ontological insecurity when relationships become negative and straining (Smart et al, 2012). Losing friends who were thought to be granted is likely to be profoundly challenging. However, some friendship relationships may be activated and play a key role in overcoming material and emotional problems (Kalmijn \& Broese van Groenou, 2005; Martin, 1994; Terhell, Broese van Groenou, \& van Tilburg, 2007).

Idealized images of friendship (Rawlins, 1992) meant that users of Internet forums took certain levels of support from friends for granted, and were not prepared for the impact that the relationship breakdown would have on their wider social networks. There was an expectation that 'couple friends' would take the side of the injured party in a break-up, or be willing to hear details of an ex-partner's faults, and when this failed to materialise in practice, users felt unsupported. In that regard, the fact that some mutual friends want to remain "neutral" and to be friend with both parties is often perceived as problematic, as it may "neutralise the friendship." When some users of Internet forums understand that mutual friends may be embarrassed ("walking on eggshells") and try their best to remain in the middle, most of the users reported how hard it is to have friends who listen to both sides and maintain an unwanted tie, especially in the case of a difficult relationship breakdown (e.g., involving infidelities). In exceptional cases, when some of the ex-partner's friends chose the users' side, it is underlined as a sign of victory, proving who the injured party really was.

Friendship is 'put to the test' in difficult moments of our lives, with a friend's failure to understand and relate perceived as a betrayal (Rebughini, 2010: 2.5). Interestingly, in the online communities, the person sharing their story systematically gets positive 
reinforcement, no matter if they were the initiator of the relationship breakdown. Other users reassure them that they believed their side of the story and that they are not to blame, but to comfort: "You are a person of great worth." However, in one thread, a user was also told to "grow up", as he cannot prevent his friends from seeing his ex-partner. There exist strong cultural expectations as to what friendship is and means (Rawlins, 1992), which led users of Internet forums to expect friends to support them through the crisis of a relationship breakdown, despite the neglect that these friendships had often suffered when users had previously prioritised their couple relationships.

Participants in the online discussion reported the unexpected surprise and pain that accompanied the loss of friends following a relationship breakdown. After the loss of the "best friend" [the partner], came the unexpected loss of the established friend group or, at least, part of it. Responses are generally supportive, framing losses as inevitable and even have to be seen as a positive outcome because friends finally reveal "their true colours" during the process. The friends who left are qualified as "shallow as puddles", "fake", "false", "superficial" and the very existence of the friendship in the first place is challenged. One user states that "the friendship was never there", while another suggests to call them "the mutuals" instead of "the mutual friends. The friends who remained faithful are the "real" or "true" friends. The real friends are the friends known previous to the relationship who, despite the years of estrangement, are there when needed, the mutual friends who have taken the participants' side, and new friends who often have had similar experiences; all together they form the new social circle. They are described as "priceless", "true gems", "worth more than gold". In the process of separating the wheat from the chaff, users stated that they will never ever invest in the "wrong" friendships and that "a few" good friends are better than many bad ones.

\section{Friendship in online communities:}

Narratives of relationship breakdown frame the trauma of the relationship ending as an emotional issue individuals have to cope with, usually with the support of close friends (Rawlins, 1992). Accounts here suggest that for users of Internet forums, the realisation that break-ups would not be supported by friends in the way that they expected was an additional trial that had to be overcome. Rather than the drawing in and support of close 
friendship bonds, users found their relationship breakdown to negatively impact other relationships; as Ketovkivi reports, 'in couple-oriented culture, losing a partner often leads to wider isolation' (2012: 484). For this reason, users sought support anonymously using pseudonyms on online message boards.

There exists a wide array of online support groups such as for substance abuse, illness (HIV/AIDS, Alzheimer's disease, Parkinson's disease), eating disorders, depression, or divorce (Campbell \& Wright, 2009). They are especially helpful for people facing a critical life event or belonging to a group sharing a marginalized or stigmatized identity. In the case of critical life events, online communities may play a key-role for exchanging information, sharing similar experiences, and receiving emotional support. For instance, for divorce, Peachter (2012b) showed that it promotes learning regarding knowledge about the law and coping with the experience itself, with some limitations though. Similarly, Attard and Coulson (2012) investigated online communication of participants with Parkinson's disease and showed that participation helped them in coping with the challenges of this condition. Online communities are also very important for people dealing with issues that make them feel marginalized or stigmatized. For instance, Christian (2005) analysed how stepmothers used online communication to contest the myth of the "wicked stepmother" by constructing positive narratives of their role, and even by reversing the stigma by calling the biological mothers "wicked" themselves. Similarly, online support proved to be helpful for childless stepmothers dealing with stepchild living arrangement and interference of the biological mother (Craig \& Johnson, 2010). Emotional support seems to be the major outcome of participation in online communities. It is more likely to be effective if the source is perceived as holding credibility (Campbell \& Wright, 2009). While family members and close friends may try to control or influence the situation, participants in online support group are less like to exert controlling behaviours on one another and, thus, be overall supportive (Campbell \& Wright, 2009). However, online communication is not always easy and fulfilling. In the case of the participants with Parkinson's disease, communication proved to be also a cause for difficulty and stress (Attard \& Coulson, 2012). When an identity is temporary, like for a relationship breakdown or a divorce, moving on and exiting the community may also become an issue. 
Support groups around intimate relationship breakdown are a response to a critical life event profoundly changing people's personal life and webs of relationships. They also gather people who feel to some extent marginalized or stigmatized by their new single status despite the increasing divorce rate. Referring back to the distinction between fake and real friends, the online friends are repetitively qualified as "real" friends and "fellows". Both websites offered the possibility of organising events in 'real life.' Users did not mention previous face-to-face encounters with each other in the threads, but some mentioned this possibility. Recommendations aim more at activities favouring friendship development and the extensive use of online communities "prescribing regular doses of support from online friends."

\section{Negotiating/Re-evaluating Friendships:}

Unlike other personal ties, friendships are inherently more open to individual negotiation (Allan, 2008), and the impact of couple relationship breakdown prompted participants to revaluate, renegotiate or sometimes overhaul friendships. Major life events such as relationship breakdown often cause the reassessment of other elements of one's personal life (Rebughini, 2010), with friendship ties taking on exceptional intensity during difficult periods. More than this, the bracketing off of various groups of intimates, and the privileging of couple relationships as the centre of personal life fails to account for the 'suffusion' (Spencer and Pahl, 2006), or overlaps and intersections between friendships and family. With the intimate couple as the central principle organising intimate life (Ketovkivi, 2012), individuals find themselves isolated without a partner or strong friendship networks. Yet the disruption and isolation caused by relationship breakdown appeared to be something users of Internet forums were ill prepared for, as they had particular expectations of the support friends would offer them. As Rawlins (1992) argues, although particular versions of friendship persist as an enduring cultural ideal, its ideal form is frequently experienced as an elusive personal reality.

Individuals in long-term relationships tend to maintain friendships which support their relationships (O'Connor, 1992), and for these users of Internet forums the transition from coupled to single was not always supported by friends in ways that they had hoped or 
expected. Relationship breakdown is often a fraught and isolating experience, which is exacerbated by dominant ideals of compulsory coupledom (Wilkinson, 2014) that label singleness a deficit identity (Moore and Radtke, 2015). With singleness highly stigmatised (Ingraham, 1996), users experienced a shift in their social standing within their networks. The ideological force of couple culture is underpinned by the assumption that everyone wants to be part of a couple, which takes priority as the most important relationship in individuals' lives (Budgeon, 2008). Care is often associated with physical proximity, meaning that we view our partners and families as our primary responsibilities (Massey, 2004), leaving friends on the periphery of personal life.

Wilkinson's (2014) research details the ways that single people are often made to feel out of place within the familial home, which has parallels with couple sociality, with normative pressures and expectations directed onto the non-coupled, who are excluded and stigmatized if they fail to conform. Users tried to make sense of their experience of social sudden disgrace by drawing on different explanations: the perceived differences in couple and single sociability (e.g. staying home versus going out) leading mutual friends to "forget" to invite them to couples' events; the potential awkwardness and heavy atmosphere created by a recently separated person; the fear of divorce contamination ("a reminder of what could easily happen to them"); and the idea that singles (especially women) are 'after' married partners. A few users also report the new partner completely replacing them in that couple to couple configuration. As an answer, users encourage themselves to have friends who share similar experiences because "only those who have walked in the boots know the deal." Thus, users involved in a new relationship get their legitimacy too as they have gone through the break-up. Not being single does not seem to be an exclusion criterion, as the emphasis is put more on the experience of being 'un-coupled' from an ex-partner.

Kipnis notes that 'those who stray from the norms of coupledom are accused of being immature or commitment phobic' (2003:156), and forum members occasionally reported being pushed to be part of a couple again to conform to dominant norms, with forming new friendships more challenging than starting new partnerships, as most websites are based on dating and matching. In the dominant social narrative, breakups are followed by the start of a new relationship, which friends often facilitated or encouraged, regardless or not whether the individual was ready. Being coupled operates as an 'order principle' organising close 
relationships into exclusive or inclusive configurations (Ketovkivi, 2012:473), with couple sociality highly exclusive. For participants, the sets of friends maintained when part of a couple are not always comfortable with their singleness, and nudging them back towards being partnered was more reflective of their needs than those of the users themselves.

For forum members, the breakdown of their primary couple relationship often effected a painful re-evaluation of their wider friendships. Friendships took on a more central role in their lives, reflecting single people's more inclusive personal relationships (Wilkinson, 2014). As Cronin's (2015) research indicated, the friendships individuals maintain when single may look very different to those of coupled people, which may be more invested in their relationships. Users of Internet forums here indicated as much, with the failure of their existing networks to support them through the transition from coupled to single. While this is an 'existential trial' (Rebughini, 2010) that represents a particularly critical life transition, on reflection, users welcomed the self-awareness that this had brought about. It is often described as a 'learning process' in users' accounts, with acknowledgment that dealing with the impact of their relationship breakdown on their friendships has been a difficult process, the outcome is worth it as friends reveal "their true colours" when called on for support. The friends who remained loyal and supportive can be relied on as "real" friends, who have passed the 'test' of friendship (Rebughini, 2010: 2.5). As well as reflecting on the issues that led to the breakdown in their relationship, being newly single often provides the space for individuals to reflect on the deprioritisation of friendship in their lives (Cronin, 2015). Particular sets of friends, and the significance of friendship, may change over the life course and through periods of transition (Jamieson et al, 2006: 3.11), with relationship breakdown being a particularly critical life event. The idea of mourning frequently appears in the threads as users recommended each other to mourn the end of lost friendships and then to move on. There is also advice about reaching out to friends to tell the other side of the break-up story (but without fighting too hard), but the main lesson is accepting the loss as "divorce means loosing friends" and as "there is a divorce settlement and a friend settlement." Some users more ahead in the break-up process also reported that some apparently lost friends may come back.

The breakdown of their relationships also rendered users' previous couple privilege visible. The lack of social recognition or value attributed to other types of social ties such as 
friendship (Budgeon, 2008), is noted by users. While they had previously neglected friends, as single people they now find themselves neglected and isolated by friends who in turn prioritise their own couple relationships. The ideological force of couple culture is such that there is discrimination against those who do not fit this path (Wilkinson, 2013), within personal life formations. Users now find themselves on the 'wrong' side of dominant cultural norms, and are forced to reflect on ways in which they may previously have supported them or neglected friends in similar positions. Taken for granted assumptions about the life course and the 'social clock' (Moore and Radtke, 2015), whereby certain accomplishments should have been achieved by certain points, are also subject to critical reflection and reassessment. In that perspective, the online communities give them a new sense of belonging and of 'normality', as they are part of a group of people experiencing the same event and similar feelings: "You are not alone."; "I know just how you feel!"

However, while there is a certain framing of a relationship breakdown and the ensuing friendship crises as ultimately a positive experience for participants, this is not always reported. Singleness, and the accompanying stigma are difficult to adjust to following the taken-for-granted privilege of being coupled. As Cobb notes, "being single is often one of the most despised sexual minority positions one could be' (2007: 456), and participants have to construct close relationships from a radically different position following relationship breakdown. Research suggests some suffer from a 'haunting of the couple' (Ketovkivi, 2012: 484), and may not always be able to construct alternative intimacies on separating from a partner. They are lonely, not adjusted to being without a partner, lacking both intimacy and support. In a highly individualised society, there is little social support for individuals going through disruptive life events, with the onus placed on the individual to find support and to readjust quickly. As Roseneil and Budgeon (2004:154) suggest, sociology needs to register a fuller range of practices of intimacy and care not limited to the couple or family.

\section{Conclusion:}

This article has demonstrated the tensions and intersections between different kinds of relationships over the life course. The centrality of the sexual couple relationship as the ideal relationship form within social life coexists with idealised representations of friendship 
as providing high levels of support during critical life transitions. For our users of Internet forums, there is little evidence to suggest a move towards more fluid, reflexive conditions (Budgeon, 2006), as relationship breakdown is challenging, and often accompanied by the unexpected loss of wider friendships, which have been poorly maintained by participants in their coupled state. A general decentring of the couple in personal life would encourage less dependence on partners for all of our emotional needs, and further recognition of the value that a network of intimates plays in all of our lives.

This increasing recognition of the value of friendship is highlighted through the analysis of online communities here. It is possible that people who are using online support groups are those facing more difficulties and experiencing more losses in their friendship network. At the same time, in the threads, users also reported positive experiences and support including old friends coming back into their lives or mutual friends not taking sides. In addition, using Internet forums has become a very common contemporary experience and is not restricted to a specific part of the population. The users of Internet forums we observed were people at different stages of the process, people who have left their partner and have been left, and together they created a narrative of friendship through making sense of losses. They reflect on their own practices before the break-up (not enough friendship maintenance, overly focused on the couple) and make positive resolutions for the future (better selection of friends, more friendship maintenance). Interestingly, even when neglected during the couple relationship, high expectations weigh on friendship relationships, as we have uncovered strict friendship norms regarding the custody of different sets of friends and the related expected support behaviours. As friends do not always behave as those in the break-up process were hoping or expecting, the relationship breakdown works as an 'ordeal' for friendship. Despite the high divorce and cohabiting relationship dissolution rates, individuals appear to be ill-prepared for the relational consequences of critical life transitions. Collectively, they resolve to improve their friendship practices and, in that regard, going through an intimate relationship breakdown is a 'learning' experience. However, questions arise as to whether these good intentions will be maintained if and when individuals form new relationships, within the context of coupledom as an entrenched social institution with specific sociability practices and norms. 


\section{References:}

Albeck, S, \& Kaydar, D, 2002, Divorced Mothers, Journal of Divorce \& Remarriage 36, 3 4, 111-138. https://doi.org/10.1300/J087v36n03 07

Allan, G, 2008, Flexibility, friendship, and family, Personal Relationships, 15, 1-16.

Amato, P.R, 2010, Research on divorce: Continuing trends and new developments, Journal of Marriage and Family, 72, 3, 650-666.

Bakker, W., Karsten, L. and Mulder, C. H, 2015, Family routines and rituals following separation: continuity and change, Families, Relationships and Societies, 4, 3, 365-8.

Beck, U. and Beck-Gernsheim, E, 2002, Individualization, London: Sage.

Beck, U. and Beck-Gernsheim, E, 1995, The Normal Chaos of Love, Cambridge: Polity Press.

British Psychological Society, 2006, Code of ethics and conduct, Leicester: British Psychological Society.

Budgeon, S, 2008, Couple Culture and the production of singleness, Sexualities, 11, 3, 301325.

Budgeon, S, 2006, 'Friendship and formations of sociality in late modernity: the challenge of 'post traditional intimacy', Sociological Research Online, 11, 3.

Christian, A, 2005, Contesting the myth of the 'wicked stepmother': narrative analysis of an online stepfamily support group, Western Journal of Communication, 69, 1, 27-47.

Cobb, M, 2007, Lonely, South Atlantic Quarterly, 106, 3, 445-457.

Couldry, N, 2008, Mediatization or mediation? Alternative understandings of the emergent space of digital storytelling, New Media \& Society, 10, 3, 373-391.

Craig, E. A., \& Johnson, A. J, 2011, Role strain and online social support for childless stepmothers, Journal of Social and Personal Relationships, 28, 6, 868-887. 
Cronin, A. M, 2015, Gendering friendship: couple culture, heteronormativity and the production of gender, Sociology, 49, 6, 1167-1182

Gabb, J., \& Fink, J, 2015, Couple relationships in the 21st century, London, England: Palgrave Macmillan

Giddens, A, 1992, The Transformation of Intimacy, Cambridge: Polity Press

Heaphy, B. Smart, C. Einarsdottir, A, 2013, Same-sex marriages: New generations, new relationships, Basingstoke: Palgrave Macmillan

Ingraham, C, 1996, The Heterosexual Imaginary, in S. Seidman (Ed.) Queer Theory/Sociology, 168-193, Oxford, Blackwell.

Jamieson, L, 1998, Intimacy: Personal relationships in modern societies, Cambridge: Polity.

Jamieson, L., Morgan, D., Crow, G. and Allan, G, 2006, Friends, Neighbours and Distant Partners: Extending or Decentring Family Relationships?, Sociological Research Online, 11, 3.

Kalmijn, M, 2003, Shared friendship networks and the life course: An analysis of survey data on married and cohabiting couples, Social Networks, 25, 3, 231-249.

Kalmijn, M., \& Broese van Groenou, M, 2005, Differential effects of divorce on social integration, Journal of Social and Personal Relationships, 22, 4, 455-476.

Ketovkivi, K, 2012, The intimate couple, family and the relational organization of close relationships, Sociology, 46, 3, 473-489.

Massey, D, 2004, Geographies of responsibility, Geografiska Annaler: Series B, Human Geography, 86, 1, 5-18.

Moore, J.A. and Radtke, L.H, 2015, Starting "Real" Life: Women Negotiating a Successful Midlife Single Identity, Psychology of Women Quarterly, 39, 3, 305-319. 
O'Connor P, 1992, Friendships between Women: A Critical Review, Hemel Hempstead: Harvester Wheatsheaf.

Office for National Statistics, 2014, Divorces in England and Wales, 2012, Available at http://www.ons.gov.uk/ons/dcp171778 351693.pdf.

Paechter, C, 2012a, Researching sensitive issues online : implications of a hybrid insider/outsider position in a retrospective ethnographic study, Qualitative Research, $13,1,71-86$.

Paechter, C, 2012b, Online Learning in Divorce: How the Formation of a Community of Practice in a Divorce Support Website Enables and Inhibits Learning, E-Learning and Digital Media, 9, 4, 392-405.

Rawlins, W. K, 1992, Friendship matters: Communication, dialectics, and the life course, New York: Aldine De Gruyter.

Rebughini, P, 2010, Friendship dynamics between emotions and trials, Sociological Research Online, 16, 3, 1

Reynolds, J and Taylor, S, 2005, Narrating singleness: Life stories and deficit identities, Narrative Inquiry, 15, 197-215.

Rubin, G, 1984, Thinking sex: Notes for a radical theory of the politics of sexuality in Abelove H, Barale M A and Halperin D M (Eds.) The Lesbian and Gay Studies Reader, New York: Routledge.

Sandfield, A. and Percy, C, 2003, Accounting for Single Status: Heterosexism and ageism in heterosexual women's talk about marriage, Feminism and Psychology, 13, 4, 475488.

Seidman, S, 2005, From polluted homosexual to the normal gay: Changing patterns of sexual regulation in America in Ingraham C (Ed.) Thinking Straight: The Power, the Promise, and the Paradox of Heterosexuality, New York; London: Routledge. 
Smart, C, 2007, Personal Life, Cambridge: Polity Press.

Smart, C, Davies, K, Heaphy, B \& Mason, J, 2012, Difficult Friendships and Ontological Security, The Sociological Review, 60, 91-109.

Spencer, L. and Pahl, R, 2006, Rethinking Friendship: Hidden Solidarities Today, Princeton: Princeton University Press

Suen, Yiu Tung, 2015, What's Gay About Being Single? A Qualitative Study of the Lived Experiences of Older Single Gay Men, Sociological Research Online, 20, 3, 7.

Terhell, E. L., Broese van Groenou, M. I., \& van Tilburg, T, 2007, Network contact changes in early and later postseparation years, Social Networks, 29, 1, 11-24.

van Hooff, J, 2015, Desires, Expectations and the Sexual Practices of Married and Cohabiting Heterosexual Women, Sociological Research Online, 20, 4, 4.

Wilkinson, E, 2013, Learning to love again: 'broken families', citizenship and the state promotion of coupledom, Geoforum, 49, 206-213.

Wilkinson, E, 2014, Single people's geographies of home: intimacy and friendship beyond 'the family', Environment and Planning A, 46, 10, 2452-2468. 